\title{
Log-normal approximation of the equity premium in the production model
}

\author{
Burkhard Heer ${ }^{\mathrm{a}, \mathrm{b}}$ and Alfred Maußner ${ }^{\mathrm{c}, *}$ \\ ${ }^{\text {a }}$ School of Economics and Management, Free University of Bozen-Bolzano, \\ 1 Piazza Università, I-39100, Bozen-Bolzano, Italy \\ ${ }^{\mathrm{b}}$ CESifo, Munich, Germany \\ ${ }^{\mathrm{c}}$ Department of Economics, University of Augsburg, Universitatsstraße 16, \\ 86159, Augsburg, Germany
}

The conditional equity premium in the model with production is often approximated by assuming a jointly log-normal distribution of the marginal rate of substitution in consumption and the marginal productivity of capital. We show that, for standard parameterization, this premium is about one-third less than that implied by a nonlinear approximation of the Euler equations.

Keywords: equity premium; log-normal approximation

JEL Classification: G12; C63; E22; E32

\section{Introduction}

In the production economy, the Euler equation of the household is given by (see, e.g. equation 10.75; Altug and Labadie, 2008):

$$
\Lambda_{t}=\beta \mathbb{E}_{t} \Lambda_{t+1} R_{t+1}
$$

where $\beta, \Lambda_{t}$ and $R_{t+1}$ denote the discount factor, the marginal utility of consumption and the return of equity in period $t+1$, respectively. The risk-free interest rate $r_{t}$ follows from

$$
r_{t}=\frac{\Lambda_{t}}{\beta \mathbb{E}_{t} \Lambda_{t+1}}-1
$$

In the asset pricing literature such as in Jermann (1998) or Altug and Labadie (2008), the asset premium is computed by assuming that the marginal rate of substitutions, $M_{t+1}:=\beta \frac{\Lambda_{t+1}}{\Lambda_{t}}$, and the equity return are distributed jointly log-normal implying the equity premium ${ }^{1}$ :

$$
\begin{aligned}
\mathbb{E}\left(R_{t+1}-1\right)-r_{t} \simeq & -0.5 \operatorname{var}\left(\ln R_{t+1}\right) \\
& -\operatorname{cov}\left(\ln M_{t+1}, \ln R_{t+1}\right)
\end{aligned}
$$

We show for the standard model of the production economy that the equity premium computed with the help of Equation 3 is one-third less than that of a more exact nonlinear approximation.

\section{The Model}

We consider a model with habit in consumption and adjustment costs in capital as in Jermann (1998) that is able to reproduce the empirically observed equity premium. We follow the description of this model in Heer and Maußner (2009). Time is discrete and denoted by $t$.

\footnotetext{
*Corresponding author. E-mail: alfred.maussner@wiwi.uni-augsburg.de

${ }^{1}$ The log-normal pricing formula 3 is derived in the Technical Appendix.
} 


\section{Households}

A representative household supplies labour in a fixed amount of $N=1$ at the real wage $w_{t}$. Besides labour income, he/she receives dividends $d_{t}$ per unit of share $S_{t}$ he/she holds in the representative firm. The current price of shares in units of the consumption good is $v_{t}$. His/her current period utility function $u$ depends on current and past consumption, $C_{t}$ and $C_{t-1}$, respectively. Given his/her initial stock of shares $S_{t}$, the households maximize

$$
\begin{gathered}
\mathbb{E}_{t} \sum_{s=0}^{\infty} \beta^{s}\left\{\frac{\left(C_{t+s}-b C_{t+s-1}\right)^{1-\eta}-1}{1-\eta}\right\} \\
\eta \geq 0, \beta \in(0,1), b \in[0,1)
\end{gathered}
$$

subject to the sequence of budget constraints

$$
v_{t}\left(S_{t+1}-S_{t}\right) \leq w_{t}+d_{t} S_{t}-C_{t}
$$

where $1 / \eta$ denotes the intertemporal elasticity of substitution. The operator $\mathbb{E}_{t}$ denotes mathematical expectations with respect to the information as of period $t$. The first-order conditions of this problem are Equation 1 and

$$
\begin{gathered}
\Lambda_{t}=\left(C_{t}-b C_{t-1}\right)^{-\eta}-\beta b \mathbb{E}_{t}\left(C_{t+1}-b C_{t}\right)^{-\eta} \\
R_{t}:=\frac{d_{t}+v_{t}}{v_{t-1}}
\end{gathered}
$$

where $\Lambda_{t}$ is the Lagrange multiplier of the budget constraint.

\section{Firms}

The representative firm uses labour $N_{t}$ and capital $K_{t}$ to produce output $Y_{t}$ according to the production function

$$
Y_{t}=Z_{t} N_{t}^{1-\alpha} K_{t}^{\alpha}, \quad \alpha \in(0,1)
$$

The level of total factor productivity $Z_{t}$ is governed by the first-order Autoregressive (AR(1)) process

$$
\ln Z_{t}=\rho^{Z} \ln Z_{t-1}+\varepsilon_{t}^{Z}, \quad \varepsilon_{t}^{Z} \sim N\left(0,\left(\sigma^{Z}\right)^{2}\right)
$$

with autocorrelation parameter $\left|\rho^{Z}\right|<1$ and innovations $\varepsilon_{t}^{Z}$. The firm finances part of its investment $I_{t}$ from retained earnings $R E_{t}$ and issues new shares to cover the remaining part:

$$
I_{t}=v_{t}\left(S_{t+1}-S_{t}\right)+R E_{t}
$$

It distributes the excess of its profits over retained earnings to the household sector:

$$
d_{t} S_{t}=Y_{t}-w_{t} N_{t}-R E_{t}
$$

Investment increases the firm's next-period stock of capital according to

$$
K_{t+1}=\Phi\left(\frac{I_{t}}{K_{t}}\right) K_{t}+(1-\delta) K_{t}, \quad \delta \in(0,1]
$$

where we parameterize the function $\Phi$ as

$$
\Phi\left(\frac{I_{t}}{K_{t}}\right):=\frac{a_{1}}{1-\zeta}\left(\frac{I_{t}}{K_{t}}\right)^{1-\zeta}+a_{2}, \quad \zeta>0
$$

The firm's ex-dividend value at the end of the current period $t, V_{t}$, equals the number of outstanding stocks $S_{t+1}$ times the current stock price $v_{t}{ }^{2}$ The first-order conditions for maximizing the beginning-of-period value of the firm subject to Equation 11 are

$$
\begin{gathered}
w_{t}=(1-\alpha) Z_{t} N_{t}^{-\alpha} K_{t}^{\alpha} \\
q_{t}=\frac{1}{\Phi^{\prime}\left(I_{t} / K_{t}\right)} \\
q_{t}=\mathbb{E}_{t} \varrho_{t+1}\left\{\alpha Z_{t+1} N_{t+1}^{1-\alpha} K_{t+1}^{\alpha-1}-\left(\frac{I_{t+1}}{K_{t+1}}\right)\right. \\
\left.+q_{t+1}\left[\Phi\left(\frac{I_{t+1}}{K_{t+1}}\right)+1-\delta\right]\right\}
\end{gathered}
$$

with $\varrho_{t+s}=\frac{1}{R_{t+1} R_{t+2} \ldots R_{t+s}}$. In addition, the transversality condition

$$
\lim _{s \rightarrow \infty} \mathbb{E}_{t} \varrho_{t+s} q_{t+s} K_{t+s+1}=0
$$

must hold.

\section{Market equilibrium}

Using Equations 9 and 10, the household's budget constraint implies the economy's resource restriction:

$$
Y_{t}=C_{t}+I_{t}
$$

In equilibrium, the labour market clears at the wage $w_{t}$ so that $N_{t}=1$ for all $t$. Furthermore, using Equation $1, \varrho_{t+1}$ can be replaced by $\beta \Lambda_{t+1} / \Lambda_{t}$ so that at any time $t$ the set of equations

\footnotetext{
${ }^{2}$ The derivation of the form value and its beginning-of-period value is delegated to the Technical Appendix.
} 


$$
\begin{gathered}
q_{t}=\frac{1}{\Phi^{\prime}\left(I_{t} / K_{t}\right)} \\
Y_{t}=Z_{t} K_{t}^{\alpha} \\
Y_{t}=C_{t}+I_{t} \\
\Lambda_{t}=\left(C_{t}-b C_{t-1}\right)^{-\eta}-\beta b \mathbb{E}_{t}\left(C_{t+1}-b C_{t}\right)^{-\eta} \\
q_{t}=\beta \mathbb{E}_{t} \frac{\Lambda_{t+1}}{\Lambda_{t}}\left\{\alpha Z_{t+1} K_{t+1}^{\alpha-1}-\left(\frac{I_{t+1}}{K_{t+1}}\right)\right. \\
\left.+q_{t+1}\left[\Phi\left(\frac{I_{t+1}}{K_{t+1}}\right)+1-\delta\right]\right\} \\
K_{t+1}=\Phi\left(\frac{I_{t}}{K_{t}}\right) K_{t}+(1-\delta) K_{t}
\end{gathered}
$$

determines $Y_{t}, C_{t}, I_{t}, K_{t+1}, \Lambda_{t+1}$ and $q_{t+1}$, given $K_{t}$, $\Lambda_{t}$ and $q_{t}$.

\section{Computation and Calibration}

We use the parameter settings from Heer and Maußner (2009, section 6.3.4). Table 1 displays the respective values. In particular, we set the discount factor $\beta$ equal to 0.994 implying an annual risk-free rate in the stationary equilibrium of $2.4 \% .^{3}$

\section{Equity premium}

The solutions of the model are functions $g^{i}, i \in\{K, Y$, $C, I, \Lambda, q\}$, that determine $K_{t+1}, Y_{t}, C_{t}, I_{t}, \Lambda_{t}$ and $q_{t}$ given the current period state variables $K_{t}, C_{t-1}$ and the $\log$ of the productivity shock $\ln Z_{t}$.

Since

$$
\begin{aligned}
\Lambda_{t+1}= & g^{\Lambda}\left(K_{t+1}, C_{t}, \ln Z_{t+1}\right) \\
= & g^{\Lambda}\left(g^{\mathrm{K}}\left(K_{t}, C_{t-1}, \ln Z_{t}\right),\right. \\
& \left.g^{C}\left(K_{t}, C_{t-1}, \ln Z_{t}\right), \varrho \ln Z_{t}+\varepsilon_{t+1}^{Z}\right) \\
= & : \tilde{g}^{\Lambda}\left(K_{t}, C_{t-1}, \rho \ln Z_{t}+\varepsilon_{t+1}^{Z}\right)
\end{aligned}
$$

Table 1. Benchmark calibration

Preferences $\beta=0.994 \quad b=0.8 \quad \eta=2 \quad N=0.13$

Production $\alpha=0.27 \quad \delta=0.011 \quad \rho^{z}=0.90 \quad \sigma^{z}=0.0072$ $\zeta=1 / 0.23$ and $\varepsilon_{t+1}^{Z}$ is normally distributed, the expected value of the Lagrange multiplier equals

$$
\begin{aligned}
\mathbb{E}_{t} \Lambda_{t+1}= & \int_{\infty}^{\infty} \tilde{g}^{\Lambda}\left(K_{t}, C_{t-1}, \rho \ln Z_{t}+\varepsilon_{t+1}^{Z}\right) \\
& \frac{1}{\sigma^{z} \sqrt{2 \pi}} e^{\frac{-\left(\varepsilon_{t+1}^{Z}\right)^{2}}{\left(\sigma^{Z}\right)^{2}}} d \varepsilon_{t+1}^{Z}
\end{aligned}
$$

We use the quadratic approximation of $g^{\Lambda}$ at the stationary equilibrium and the Gauss-Hermite 6-point quadrature formula to approximate the integral on the right-hand side of this equation.

The labour market equilibrium condition 13 and Equation 11 imply that the right-hand side of Equation 15 can be written as

$$
\begin{aligned}
1 & =\beta \mathbb{E}_{t} \frac{\Lambda_{t+1}}{\Lambda_{t}} \frac{Y_{t+1}-w_{t+1} N_{t+1}-I_{t+1}+q_{t+2} K_{t+2}}{q_{t} K_{t+1}} \\
& =\beta \mathbb{E}_{t} \frac{\Lambda_{t+1}}{\Lambda_{t}} \frac{d_{t+1}+v_{t+1}}{v_{t}}=\beta \mathbb{E}_{t} \frac{\Lambda_{t+1}}{\Lambda_{t}} R_{t+1}
\end{aligned}
$$

where the second equality follows from Equations 9 and 10 and the observation that $q_{t} K_{t+1}=v_{t} S_{t+1}$ (Heer and Maußner, 2009, p. 317). Therefore, the gross rate of return on the shares of the representative firm equals ${ }^{4}$

$$
R_{t+1}=\frac{\alpha Y_{t+1}-I_{t+1}+q_{t+1} K_{t+2}}{q_{t} K_{t+1}}
$$

We use a random number generator to compute a long artificial time series for $R_{t+1}-r_{t}$ for a time series of 1000000 observations. The average of this time series is our measure of the ex post equity premium implied by the model.

\section{Results}

Computing the equity premium with the help of the nonlinear approximation of Equation 24 we find an average annual risk-free rate of about $1.0 \%$ and an equity premium of $4.0 \%$. Using the same data, Equation 3 yields an annual risk premium of $2.66 \%$, and, thus, about $1.3 \%$ points smaller than the risk premium implied by Equations 2 and $24 .{ }^{5}$ In Table 2, we report sensitivity analysis for other parameter values $\delta=2.5 \%, \eta \in\{1,4\}$ and $\alpha=0.36$ that are frequently used in the real-business-cycle literature.

\footnotetext{
${ }^{3}$ The Fortran computer programmes can be downloaded from http://www.wiwi.uni-augsburg.de/vwl/maussner/lehrstuhl/pap/ hm_ln.zip.

${ }^{4}$ Note $\alpha Y_{t+1}=Y_{t+1}-w_{t+1} N_{t+1}$.

${ }^{5}$ In the Technical Appendix, we test and confirm the assumption of log-normal distribution implicit in Equation 3.
} 
Table 2. Sensitivity analysis

\begin{tabular}{lll}
\hline$\{\alpha, \delta, \eta\}$ & \multicolumn{2}{l}{ Equity premium using } \\
$(3.1)$ & $(1.3)$ \\
\hline $0.36,0.011,2.0\}$ & 2.81 & 1.80 \\
$\{0.27,0.025,2.0\}$ & 3.06 & 1.99 \\
$\{0.27,0.011,1.0\}$ & 2.30 & 1.66 \\
$\{0.27,0.011,4.0\}$ & 5.97 & 3.69 \\
\hline
\end{tabular}

These values confirm our results that the use of the log-normal approximation may result in a significant lower value for the equity premium.

\section{References}

Altug, S. and Labadie, P. (2008) Asset Pricing for Dynamic Economies, Cambridge University Press, Cambridge, UK.

Heer, B. and Maußner, A. (2009) Dynamic General Equilibrium Modeling, 2nd edn, Springer, Berlin.

Jermann, U. J. (1998) Asset pricing in production economies, Journal of Monetary Economics, 41, 257-75.

Stephens, M. A. (1974) EDF statistics for goodness of fit and some comparisons, Journal of the American Statistical Association, 69, 730-7.

\section{Technical Appendix}

\section{Derivation of the firm value and Equation 24}

The firm value is equal to the value of the outstanding shares implying

$$
\begin{aligned}
V_{t} & =v_{t} S_{t+1} \stackrel{(\text { Equation 9) }}{=} I_{t}+v_{t} S_{t}-R E_{t} \stackrel{(\text { Equation 10) }}{=} \\
& I_{t}+w_{t} N_{t}-Y_{t}+\left(v_{t}+d_{t}\right) S_{t} \stackrel{\text { (Equation 6) }}{=} I_{t}+w_{t} N_{t} \\
& -Y_{t}+R_{t} V_{t-1}
\end{aligned}
$$

Rearranging and taking expectations as of period $t$, yields

$$
V_{t}=\mathbb{E}_{t}\left\{\frac{Y_{t+1}-w_{t+1} N_{t+1}-I_{t+1}+V_{t+1}}{R_{t+1}}\right\}
$$

Iterating on this equation using the law of iterated expectations and assuming

$$
\lim _{s \rightarrow \infty} \mathbb{E}_{t}\left\{\frac{V_{t+s}}{R_{t+1} R_{t+2} \ldots R_{t+s}}\right\}=0
$$

establishes that the end-of-period value of the firm equals the discounted sum of its future cash flows $C F_{t+s}=Y_{t+s}-w_{t+s} N_{t+s}-I_{t+s}$ :

$$
V_{t}=\mathbb{E}_{t} \sum_{s=1}^{\infty} \varrho_{t+s} C F_{t+s}, \quad \varrho_{t+s}=\frac{1}{R_{t+1} R_{t+2} \ldots R_{t+s}}
$$

The firm's objective is to maximize its beginning-ofperiod value, which equals $V_{t}^{\text {bop }}=V_{t}+C F_{t}$. Defining $\varrho_{t}=1$ allows us to write

$$
V_{t}^{\mathrm{bop}}=\mathbb{E}_{t} \sum_{s=0}^{\infty} \varrho_{t+s} C F_{t+s}
$$

The first-order conditions for maximizing $V_{t}^{\text {bop }}$ subject to Equation 11 are given by Equations 13-16.

\section{Deterministic stationary equilibrium}

Since our solution strategy rests on a second-order approximation of the model, we must consider the stationary equilibrium of the deterministic counterpart of our model that we get if we put $\sigma^{Z}=0$ so that $Z_{t}$ equals its unconditional expectations $Z=1$ for all $t$. In this case we can ignore the expectations operator $\mathbb{E}_{t}$. Stationarity implies $x_{t+1}=x_{t}=x$ for any variable in our model. As usual, we specify $\Phi$ so that adjustment costs play no role in the stationary equilibrium, that is $\Phi(I / K) K=\delta K$ and $q=\Phi^{\prime}(\delta)=1$. This requires that we choose

$$
\begin{aligned}
& a_{1}=\delta^{\zeta} \\
& a_{2}=\frac{-\zeta \delta}{1-\zeta}
\end{aligned}
$$

These assumptions imply via Equation 22 the stationary solution for the stock of capital:

$$
K=\left(\frac{1-\beta(1-\delta)}{\alpha \beta}\right)^{\frac{1}{\alpha-1}}
$$

Output, investment, consumption and the stationary solution for $\Lambda$ are then given by

$$
\begin{gathered}
Y=K^{\alpha} \\
I=\delta K \\
C=Y-I \\
\Lambda=C^{-\eta}(1-b)^{-\eta}(1-b \beta)
\end{gathered}
$$


Table A1. Tests of normality

\begin{tabular}{llc}
\hline Statistic & Value & Probability \\
\hline Gross return on equity & & \\
$\quad$ Lilliefors $D$ & 0.000654 & $>0.1$ \\
Cramer-von Mises $W^{2}$ & 0.071529 & 0.2671 \\
Watson $U^{2}$ & 0.067303 & 0.2675 \\
$\quad$ Anderson-Darling $A^{2}$ & 0.472767 & 0.2432 \\
Marginal rate of substitution & & \\
$\quad$ Lilliefors $D$ & 0.000783 & $>0.1$ \\
Cramer-von Mises $W^{2}$ & 0.090827 & 0.1502 \\
Watson $U^{2}$ & 0.081983 & 0.1659 \\
Anderson-Darling $A^{2}$ & 0.570298 & 0.1393 \\
\hline
\end{tabular}

\section{Derivation of the log-normal pricing formula 3}

Instead of using Equation 24 some authors compute the equity premium via Equation 1 assuming that the marginal rate of substitution $M_{t+1}:=\beta \Lambda_{t+1} / \Lambda_{t}$ and the gross return on equity $R_{t+1}$ follows a log-normal distribution.

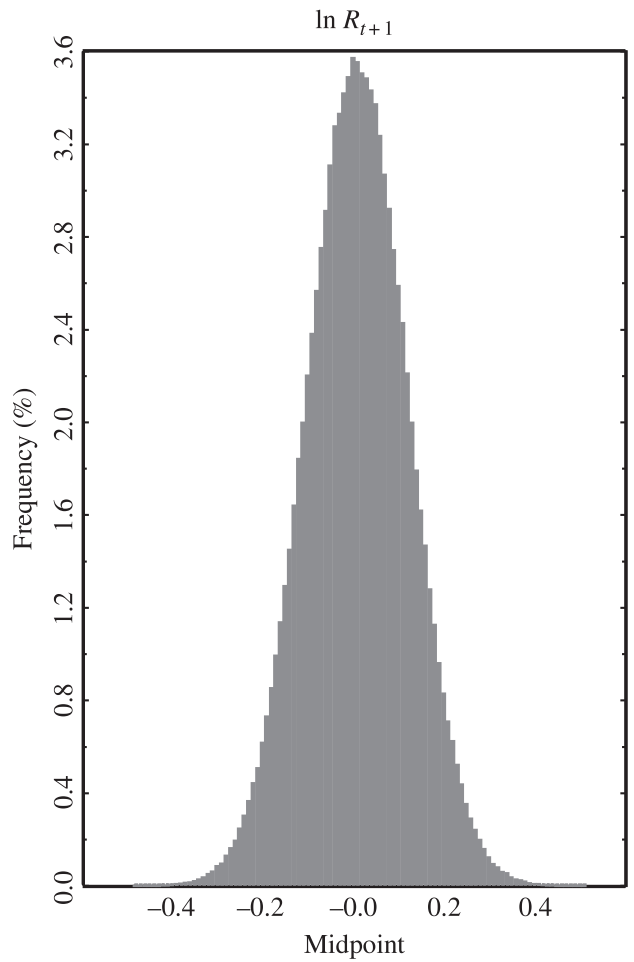

In order to use this approach, notice that Equation 1 holds also unconditionally. Now, let $a:=\ln M$ and $b:=\ln R$ denote the natural logarithms of the marginal rate of substitution and the gross return on equity, respectively, and assume $a \sim N\left(\mu_{a}, \sigma_{a}^{2}\right)$ and $b \sim N\left(\mu_{b}, \sigma_{b}^{2}\right){ }^{6} \quad$ Then, $\quad \mathbb{E}(a+b)=\mu_{a}+\mu_{b} \quad$ and $\operatorname{var}(a+b)=\sigma_{a}^{2}+\sigma_{b}^{2}+2 \operatorname{cov}(a, b)$. Since $X:=e^{a+b}$ $=M R$, the formula for the expectation of a lognormally distributed variable $X, E(X)=e^{\mu_{x}+0.5 \sigma_{x}^{2}}$, implies

$$
\mathbb{E}(M R)=e^{\mu_{a}+\mu_{b}+0.5 \sigma_{b}^{2}+\operatorname{cov}(a, b)}
$$

According to Equation 1 this expectation equals 1. Thus, by setting the $\log$ of the previous equation equal to 0 (and by putting $\mu_{a}=\mathbb{E}\left(\ln M_{t+1}\right)$, $\sigma_{a}^{2}=\operatorname{var}\left(\ln M_{t+1}\right)$ and analogously for $\mu_{b}$ and $\left.\sigma_{b}^{2}\right)$ :

$$
\begin{aligned}
\mathbb{E}\left(\ln R_{t+1}\right)= & -\mathbb{E}\left(\ln M_{t+1}\right)-0.5 \operatorname{var}\left(\ln M_{t+1}\right) \\
& -0.5 \operatorname{var}\left(\ln R_{t+1}\right)-\operatorname{cov}\left(\ln M_{t+1}, \ln R_{t+1}\right)
\end{aligned}
$$

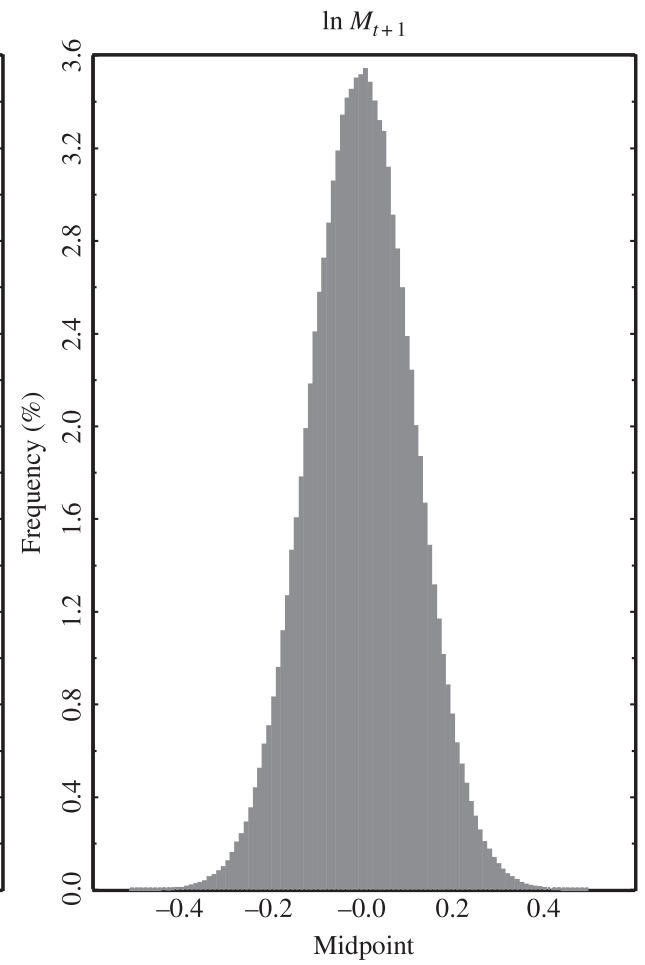

Fig. A1. Histograms of $\ln R_{t+1}$ and $\ln M_{t+1}$

\footnotetext{
${ }^{6}$ For ease of exposition, we drop the time indices momentarily.
} 
Equation 2 implies a similar formula for the gross riskfree rate $\left(1+r_{t}\right)$, namely, ${ }^{7}$

$$
\ln \left(1+r_{t}\right)=-\mathbb{E}\left(\ln M_{t+1}\right)-0.5 \operatorname{var}\left(\ln M_{t+1}\right)
$$

Thus, the expected return on equity obeys ${ }^{8}$

$$
\begin{aligned}
\mathbb{E}\left(R_{t+1}-1\right)-r_{t} \simeq & \mathbb{E}\left(\ln R_{t+1}\right)-\ln \left(1+r_{t}\right) \\
= & -0.5 \operatorname{var}\left(\ln R_{t+1}\right) \\
& -\operatorname{cov}\left(\ln M_{t+1}, \ln R_{t+1}\right)
\end{aligned}
$$

To use this equation, the variance and covariance term have to be approximated by time series averages obtained from simulations of the model. Thus, by the law of large numbers, they estimate unconditional moments. Analogously, if we use time series averages to compute the equity premium from $(1 / T) \sum_{t=0}^{T} R_{t+1}-r_{t}$, we derive an estimate of the unconditional expected equity premium.

\section{Assumption of log-normal distribution}

Figure A1 illustrates that the distribution assumption with respect to the natural logs of the gross return on equity $R_{t+1}$, and the marginal rate of substitution $M_{t+1}$ is well justified. Empirical distribution tests (conducted with EViews 7.0) do not reject the null hypothesis of normality. Table A1 reports several test statistics and their respective probability values as described, for example, in Stephens (1974).

\footnotetext{
${ }_{8}^{7}$ Since $\operatorname{var}\left(\ln \left(1+r_{t}\right)\right)=0$ and $\operatorname{cov}\left(\ln M_{t+1}, \ln \left(1+r_{t}\right)\right)=0$ and $\mathbb{E} \ln \left(1+r_{t}\right)=\ln \left(1+r_{t}\right)$.

${ }^{8}$ Since $\ln (1+x) \simeq x$.
} 